\title{
REMOTE SENSING OF SNOW IN HIGH MOUNTAIN BASINS IN NORWAY
}

\author{
by
}

\section{T. ANDERSEN AND N. HAAKENSEN}

Norwegian Water Resources and Electricity Board (NVE), Postboks 5091, Majorstua, 0301 Oslo 3, Norway

\begin{abstract}
Information on snow conditions in high mountain river basins is of vital interest for flood predictions and power production. Based on techniques derived for mapping of snow cover from digital NOAA-data, relations are established between snow covered area and remaining snow storage for three basins in southern Norway. Together with estimates of the precipitation and information on maximum accumulated snow, the relation can be useful in run-off predictions for the snow-melt period.
\end{abstract}

\section{INTRODUCTION}

Measuring snow storage in high mountains and remote areas is difficult, due to high transportation costs and weather constraints. Almost the entire electric energy production in Norway originates from hydroelectric power. Many of the largest water reservoirs receive most of their water from melting snow. Knowledge of the snow conditions in mountain areas in Norway is therefore of vital interest for water power production and flood prediction.

Manual snow surveys are made in several basins once or twice each winter. In addition the gamma-ray method is used for snow surveys in nine selected high mountain basins. Other methods are being investigated and tested. During recent years several attempts have been made to establish operative routines for snow mapping based upon satellite data. The use of satellite data was tried relatively early in Norway (Østrem 1975), and activities have been undertaken to develop methods designed for operative use (Andersen and Ødegaard 1980).

\section{LIMITATIONS}

LANDSAT data were first tested for detailed snow surveys (Ødegaard and Østrem 1977). However, due to infrequent coverage and heavy cloud cover, it soon became clear that only daily coverage would satisfy our requirement to obtain useful information during the melt season. Satellites in the NOAA series cover Norway several times daily in their polar orbits. The resolution is not as good as in the LANDSAT data, but sufficient to give useful information on snow conditions in the mountains $(900 \mathrm{~m} \mathrm{x}$ $900 \mathrm{~m}$ ). Consequently, only NOAA data have been used in recent years.

\section{AVAILABILITY OF DATA}

At the Norwegian Water Resources and Electricity Board digital satellite data were collected which were acquired during days of cloudfree or almost cloudfree conditions. The melt season extends from May through July and mainly data from this period have been collected. All data have been grouped in the following three classes: (1) complete cloud cover over all selected basins; (2) one or more basins cloudfree; (3) all basins completely cloudfree.

A survey of all data indicate that an average of seven images per melt season could be used for further analysis of all basins. On approximately 13 images only, one or more basins were visible. For the rest of the images cloud cover prevented further analysis. During June, which is the most important month during the melt season, we found on average two images where all basins were cloudless and six images where only one or two of the basins were visible.

This number of images, although not very large, proved sufficient to produce useful information concerning melt water production. For operational use, the problem is that we do not know when useful images may be available.

\section{METHODS FOR SNOW MAPPING FROM SATELLITE DATA}

Presently existing sensors available for snow studies can give information only of the areal distribution of snow cover. Density of the snow or its water equivalent cannot be obtained for basins of operational interest. Data from satellites in the NOAA series are received by the satellite tracking station in Tromsø, northern Norway. On the same day the data tape can be sent by air to the processing centre. Processed data on snow coverage can then be distributed within one or two days.

As the first step of the data processing the images are geometrically corrected by the use of known reference points. By studying reference areas with known snow conditions, a linear relationship is established between snow coverage and the grey-scale value of the pixels. A map is then constructed, showing snow cover as a percentage within each of the drainage basins. The total snow-covered area is calculated from the map. Figure 1 shows such a map of snow coverage in a basin. The method is described in detail by Andersen (1982).

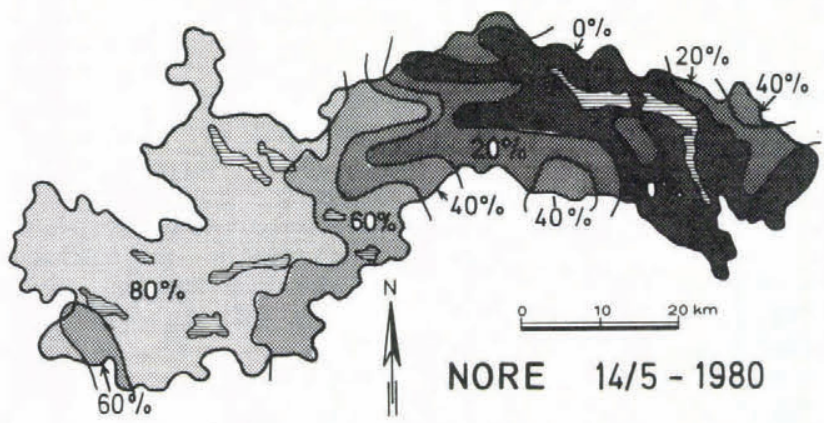

Fig.1. Map showing snow cover in percent in the Nore catchment area on 14 May 1980, based on digital NOAA data.

\section{VERIFICATION OF THE CALCULATION METHOD}

The linear relation between snow coverage and reflectance may not be mathematically correct or unambiguous. However, local snow distribution in the Norwegian high mountains as well as snow-melt processes are almost identical from year to year, and the above-mentioned uncertainty does not cause any large problem. On the other hand it is assumed that the method underestimates the areal extent of snow during the latter part of the melt season because older snow has lower reflectance than fresh snow.

The algorithm has been tested by ground truth measurements, using both meteorological data and photographs taken from low-flying aircraft. The tests show that the relation between reflectance and snow cover is a sufficiently good approximation. Currently the collected material is not sufficient to indicate improvements of the algorithm. 


\section{MELTWATER DISCHARGE FROM THE SNOW-COVER} BASINS

Existing sensors do not give information on snow depth or water equivalent of the snow. Therefore, the available information on snow coverage must be used to produce forecasts for meltwater run-off.

Earlier investigations have given good correlations between snow-covered areas and meltwater discharge from the remaining snow (Rango 1975). We have tried to find a similar relation for Norwegian high mountain areas. Based on NOAA data the following water power basins have been investigated: Nore $\left(2195 \mathrm{~km}^{2}\right)$, Mår $\left(759 \mathrm{~km}^{2}\right)$ and Songa (575 $\mathrm{km}^{2}$ ) which are all located in central southern Norway, between 750 and $1500 \mathrm{~m}$ a.s.1. (see Figure 2).

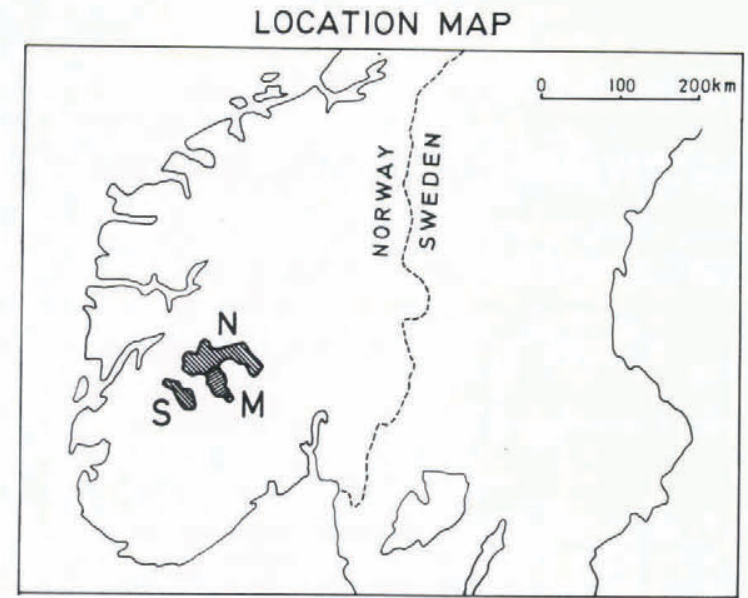

Fig.2. Location map showing the investigated catchments, all situated in central southern Norway. $\mathrm{N}=$ Nore, $\mathrm{M}=\mathrm{Mår}$, $\mathrm{S}=$ Songa .

Snow-covered areas at various times during the period 1979-83 were identified on satellite images according to the method described above. The snow storage at the end of the accumulation period is known from measurements. In addition information on precipitation and observed water discharge were used in a water balance study to determine the remaining snow storage at the dates of the satellite images. Consecutive values of snow coverage and snow storage are plotted in a diagram.

Attempts have been made to take into account the variation in the snow conditions from year to year. Martinec (1980) proposed to compare the snow cover with the ratio of the current snow accumulation to the maximum accumulation during each year. This was done for the basins in study and the correlation was slightly improved (see Figure 3).

The diagram, in this case for the Nore basin, shows a relative good relation between snow-covered area and remaining snow storage. The relation is:

$$
y=1.38 x-1.91
$$

where $y$ is the remaining snow storage in percent of maximum snow storage and $x$ is snow-covered area in percent. The correlation coefficient is 0.97 . Results from the two other basins are slightly less convincing. Further studies will be carried out for other basins.

Even a relatively coarse relation will be useful to produce meltwater forecasts. The maximum snow accumulation is measured each year in a number of basins. Together with an estimate of liquid precipitation during the rest of the melt season, such relations can be used to give a fairly reliable forecast of expected total inflow into reservoirs. Deterministic models with areal snow distribution as a parameter may be updated by means of information on the snow coverage.

A Nordic cooperating project is underway to develop an operative model which has the possibility of updating snow storage by using data from satellites.

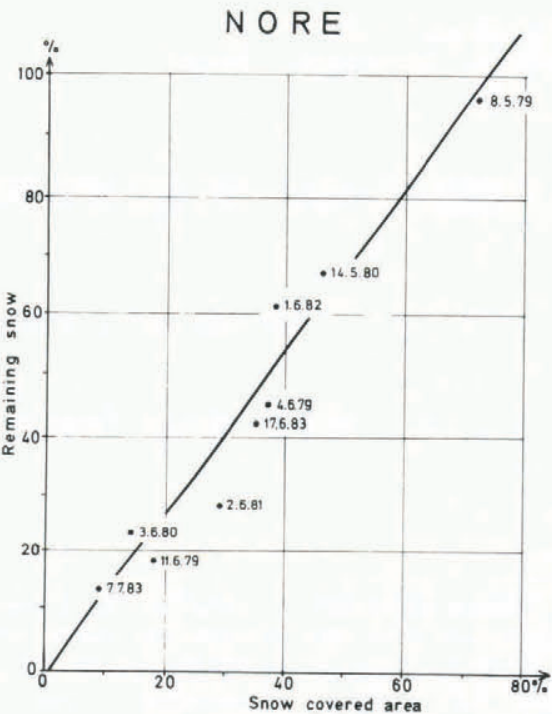

Fig.3. Results of investigations from the Nore catchment showing the relation between snow covered area as seen from the satellite, and remaining snow storage in percent of maximum snow accumulation for each year under study.

\section{CONCLUSION}

We have limited current use of satellite data to study snow conditions in high mountain areas. The resolution is not good enough to study small areas, and the number of received images is too small to study on-going processes in the snow cover. Finally, the frequent cloud coverage makes an operative use of satellite data impractical or even impossible in certain periods.

However, even those data which have been received have proved useful. Routines for handling the data have been established, and when cloudfree images have been available, the satellite images have given valuable information on the snow conditions. The simple relation which has been established between snow coverage and meltwater run-off from a given basin is sufficiently good for a semi-operative forecasting service.

We hope that satellites and new sensors may give data more suitable for hydrological use. The main problem may be to develop those sensors and suitable algorithms which together can give information on snow conditions independent of cloud cover.

\section{REFERENCES}

Andersen T 1982 Operational snow mapping by satellites. Proceedings of the Exeter Symposium July, 1982. IAHS publication no 138: 149-154

Andersen T, Ødegaard H 1980 Application of satellite data for snow mapping. Norwegian National Committee for Hydrology, Report no 3

Martinec J 1980 Limitations in hydrological interpretations of the snow coverage. Nordic Hydrology 11(5): 209-220

Rango A 1975 An overview of the applications systems verification test on snowcover mapping: 1-12 In: Operational applications of satellite snowcover observations. NASA SP-391

Ødegaard H, Østrem G 1977 Application of satellite data for snow mapping. Rapport no 9-77. NVE-Division of Hydrology

Østrem G 1975 ERTS data in glaciology - an effort to monitor glacier mass balance from satellite imagery. Journal of Glaciology 15(73): 403-415 